\section{To all those who know nothing about diabetes}

k am a teenager with diabetes and I know what it is like. Many people have preconceptions about what diabetes is. One question I love is "Is it contagious?". Diabetes is a disease of two parts. Type 1 is the type I have. This is the nasty one with injections and blood, ha-ha. No, only joking. I have to do a BM (blood monitor) four times a day before I do my insulin. It is only a pinprick of blood and not the Niagara Falls that some people believe it is. Then I have to take four insulin injections through the day. One at breakfast, one at lunch and two injections at teatime so I don't have to do one before bed. I am on a basal-bolus insulin regime. This is a fairly new type and it gives us a new found freedom. With the old insulin you had to take it half an hour before your meal but this new insulin means that you take it just before you eat, I know this doesn't sound that big a deal but it is if you are starving and can smell fish and chips! You take the bolus part before you eat and the basal part at the same time every day. The basal part keeps your blood sugar levels at a constant flow and you take the bolus part before you eat or slightly after to take down the peak from the food.

From the day you first enter the beige walled, green carpeted world of the know it all "specialists" it is drummed into you to eat your fruit and veg and your bread and pasta. But the reality is that the more carbohydrates you eat the higher your blood levels will go. But the "specialists" are too pig headed to admit it and are still telling the newly diagnosed petrified parents of type 1 kids that they must stick to the bread and
To all those paediatric endocrinologists who look fondly on their demure and compliant young patients, don't underestimate adolescent intuition. But are we bothered?

veg if they want their child to be the super model patient. Well. I'll tell you right now I am not and never will be the model patient. Malted milk biscuits are just too much of a temptation. But then again, maybe the so-called "specialists" don't know what else to tell us. The "specialists" have no idea at all. From the minute they started learning about diabetes at medical college they have been told to use the manual, the textbook, the bible of diabetes; but the truth is there isn't one, because if there was we would all want a copy. We would read it, laugh at it, cry at ourselves, then burn it ceremoniously on a bonfire.

But what really gets my wick is the over helpful person who thinks they know it all because they read an article that said that diabetic patients need their hand held across the road. The view across the country now is that if you have diabetes then you are or once were obese. This is just ridiculous, as type 1 doesn't have any scientific link to obesity. When will these people realise to back off and treat us with respect rather than pity? Don't get me wrong, I don't feel sorry for myself. I quite like having diabetes. It has become my friend, as I see it, there are a lot more dangerous and dreadful diseases out there that I could have. I am not crippled or disabled and diabetes isn't really that bad. I mean, I can use it as an excuse for anything (but only with the inexperienced). For example, P.E. If there is a disgusting, spotty, smelly adolescent asks you for a twirl during social dance you can say "Sorry, I'm hypo" and wait for a better offer to come along. Meanwhile the spotty Herbert has to dance with the P.E. teacher who is trying to smile but is failing miserably. You understand that dire circumstances call for drastic action. I would never do it in any serious situation. I'm a good diabetic really!

But seriously, we "sicklys" have to take care of ourselves for the future. We may be resilient now, when we are young, but it will catch up on us when we are older. I had a scare recently when I had a really sore back right beside my kidneys and thought "Oh my God, I am going to die", but after a cup of tea and an afternoon nap I was alright and realised the pain was caused by a over tight belt (no doubt the malted milks again!). And a final message to OPPs (over protective parents). Do not worry about us young un's. We do realise that no insulin equals the hospital or the undertakers so no need to ask us every half an hour "Did you do your insulin before that last meal?".

Teresa Chalmers

Correspondence to: $\mathrm{Dr} \mathrm{H}$ Marcovitch, Syndication Editor, BMJ Publications; h.marcovitch@btinternet.com 